\title{
Lexical complexity and fixation times in reading: Effects of word frequency, verb complexity, and lexical ambiguity
}

\author{
KEITH RAYNER and SUSAN A. DUFFY \\ University of Massachusetts, Amherst, Massachusetts
}

\begin{abstract}
Two experiments investigated whether lexical complexity increases a word's processing time. Subjects read sentences, each containing a target word, while their eye movements were monitored. In Experiment 1, mean fixation time on infrequent words was longer than on their more frequent controls, as was the first fixation after the infrequent target. Fixation times on causative, factive, and negative verbs and ambiguous nouns were no longer than on their controls. Further analyses on the ambiguous nouns, however, suggested that the likelihood of their various meanings affected fixation time. This factor was investigated in Experiment 2. Subjects spent a longer time fixating ambiguous words with two equally likely meanings than fixating ambiguous words with one highly likely meaning. The results suggest that verb complexity does not affect lexical access time, and that word frequency and the presence of two highly likely meanings may affect lexical access and/or postaccess integration.
\end{abstract}

During reading, our eyes move approximately four times per second. It is during the pauses of the eyes (the fixations) that new information is extracted from the text. Although the average duration of a fixation is $200-250 \mathrm{msec}$, there is considerable variability in the duration of any single fixation (Rayner, 1978). Fixation durations range from $100 \mathrm{msec}$ to over $500 \mathrm{msec}$, even for fairly simple text. There is now a fair amount of evidence to indicate that some of the variability is due to systematic differences in the ease of processing the words in the text. For example, words that are constrained by or predictable from the context receive shorter fixations than do words that are not constrained by or predictable from the context (S. F. Ehrlich \& Rayner, 1981; Zola, 1984). Likewise, words that are frequently used receive shorter fixations than words that are infrequent in the language (Inhoff, 1984; Just \& Carpenter, 1980; Rayner, 1977). Finally, the grammatical category of a word can influence fixation time; the main verb in simple declarative sentences receives longer fixations than do subject or object nouns (Holmes \& O'Regan, 1981; Rayner, 1977). These pieces of evidence all point to the conclusion that much of the variability in fixation duration during reading is due to the ease (or difficulty) with which certain words can be processed. It is also clear that a number of other factors can influence the amount of time that a word is looked at. These other factors include the minimal oculomotor

This research was supported by Grant HD-17246 from the National Institutes of Health and by Grant BNS-8510177 from the National Science Foundation. The study was conducted while the second author held a NIMH postdoctoral traineeship at the University of Massachusetts. We thank Charles Clifton, Alice Healy, and two anonymous reviewers for comments on an earlier draft of this paper. Requests for reprints should be sent to K. Rayner, Psychology Department, University of Massachusetts, Amherst, MA 01003. reaction time of the eye (Rayner, Slowiaczek, Clifton, \& Bertera, 1983), parafoveal preview effects (Balota, Pollatsek, \& Rayner, 1985; Rayner, 1975), syntactic parsing effects (Frazier \& Rayner, 1982; Rayner, Carlson, \& Frazier, 1983), and higher order semantic integration effects (K. Ehrlich \& Rayner, 1983; Just \& Carpenter, 1980).

The view that fixation time on a target word reflects the processing of that word is bolstered by evidence showing that the perceptual span in reading is quite small (see Rayner, 1984). The perceptual span, or area of effective vision, extends from 3 or 4 character spaces to the left of fixation to about 15 character spaces to the right. However, the span of word identification is much smaller than this. Readers primarily identify the word currently fixated, and there is no evidence to suggest that the meanings of yet-to-be-fixated words in parafoveal vision influence the current fixation; the parafoveal preview effects (Balota et al., 1985; Rayner, 1975) that have been demonstrated have not provided evidence for semantic or lexical processing of parafoveal words. Sometimes readers identify the word to the right of fixation. However, in such cases, they generally skip over that word on their next saccade. Thus, the available evidence suggests that readers primarily devote their attention to processing the fixated word and that fixation time on the word reflects the ease or difficulty of processing that word. In the experiments reported here, we took advantage of such evidence and examined the effect of lexical complexity of a target word on the fixation time for that word.

In a recent paper, Cutler (1983) discussed a number of factors that may make processing more difficult and hence produce longer fixations on particular words. These factors in one way or another cause the lexical representation for a word to be complex. For example, the representation for an ambiguous word may be more com- 
plex than that for an unambiguous word, because it includes two or more meanings. A word with a complex lexical representation might be expected to have longer fixations for at least two reasons. First, Cutler suggested that lexically complex representations might be more difficult to access in the lexicon. Second, complex meanings may be more difficult to integrate with the sentence context once lexical access is completed. Cutler used a phoneme monitoring task to test the claim that lexical complexity increases the processing required for a word; she found no effect of lexical complexity. Because there is some question about exactly what is measured by the phoneme monitoring task (Mehler, Segui, \& Carey, 1978; Newman \& Dell, 1978), and because we were interested in the extent to which lexical complexity might affect fixation time on a word, we asked subjects to read sentences in which lexical complexity was varied. We used fixation time as the dependent variable. We chose to focus on lexically ambiguous nouns and lexically complex verbs. In addition, we looked at word frequency, a lexical factor that has been found to affect fixation times. Below we discuss these lexical factors in more detail.

\section{Word Frequency}

Word frequency has long been known to exert a powerful influence on various word recognition tasks, although the nature of the effect is currently under debate (see Balota \& Chumbley, 1984, 1985; Chumbley \& Balota, 1984). A number of reading experiments have demonstrated that readers spend more time looking at lowfrequency words than at high-frequency words (Inhoff, 1984; Just \& Carpenter, 1980; Rayner, 1977). Unfortunately, all prior investigations examining the relationship between word frequency and looking time confounded word length with word frequency. Indeed, Kliegl, Olson, and Davidson (1982) argued that Just and Carpenter's (1980) finding that low-frequency words are fixated for longer periods of time may have been artifactual because low-frequency words are on the average longer than high-frequency words. Because longer words are more likely to have more than one fixation, this may have inflated the gaze duration measure used by Just and Carpenter. We asked subjects to read sentences like those below, in which target word length was controlled, and we examined fixation times on high- and low-frequency target words. The high-frequency targets are in parentheses.

The slow waltz (music) captured her attention.

The exhausted steward (student) left the plane.

\section{Verb Complexity}

A number of linguists and psychologists have claimed that a word's meaning is represented in terms of its semantic components (e.g., Bierwisch, 1970; Katz, 1972; Kintsch, 1974; Norman \& Rumelhart, 1975; Schank, 1972). Although this claim has intuitive appeal, it has been questioned on both theoretical and empirical grounds (J. D. Fodor, J. A. Fodor, \& Garrett, 1975; J. A. Fodor,
Garrett, Walker, \& Parkes, 1980; Kintsch, 1974). One prediction that derives from the componential approach concerns the relative complexity of meaning representations for lexical items. For example, the componential representation for the verb kill might be cause to die; this representation is more complex than that of the verb die (which lacks the causal element). Such comparisons have invited the hypothesis that the lexical access time and integration time for a word might be influenced by the complexity of its meaning representation. We tested this hypothesis for three kinds of complex verbs: decomposable causatives, factives, and negatives.

A number of researchers have investigated the issue of whether causative verbs such as kill and convince are represented in terms of their component meanings (cause to die, cause to believe). Earlier studies found no evidence that decomposable words are more difficult to process than their simpler components (Cutler, 1983; Kintsch, 1974). These studies used phoneme monitoring, lexical decision time, and sentence comprehension time as dependent variables. We tested the claim that causatives are more difficult to process by examining fixation times on causative and noncausative verbs in sentences such as the following (the noncausative verbs are in parentheses):

The policeman frightened (encountered) the little girl.

Paul never convinced (understood) the new president.

Cutler (1983) argued that lexical presuppositions are part of the definitions of words, and thus are stored as part of their mental representations. For example, a factive verb presupposes that its sentence complement expresses a true proposition. This presupposition may be stored with each factive verb in the mental lexicon. When such a verb is encountered in a sentence, retrieval of its meaning might include retrieval of this presupposition. Accessing or integrating this complex representation might be expected to be more time consuming than accessing or integrating the representation of a verb that lacks this presupposition. We tested this claim by comparing fixation times on factive versus nonfactive verbs, using sentences such as the following (the nonfactive verbs are in parentheses):

The girl noticed (insisted) that the cake was moldy.

The maid forgot (implied) that the sailor had left.

Finally, we examined fixation times associated with negative verbs. Negation has been shown to result in increased reaction times in a number of psycholinguistic tasks (e.g. , Carpenter \& Just, 1975; Clark \& Chase, 1972, Clark \& Clark, 1977; Just \& Clark, 1973; Sherman, 1973, 1976; Trabasso, Rollins, \& Shaughnessy, 1971). As was the case with decomposable causatives, the claim has been made (see Cutler, 1983) that the lexical representation of negative verbs contains the negative element. For example, dislike means not to like and doubt means not to believe. Thus, the lexical representation for negative verbs is more complex than that for their nonnegative counterparts. This complexity of representation might be expected to cause increased processing difficulty for negative verbs. 
We tested this claim by examining fixation times for negative and nonnegative verbs in sentences such as the following (the nonnegative verbs are in parentheses):

The teacher despised (rewarded) the unhappy child.

The fireman ignored (advised) the town council.

\section{Lexical Ambiguity}

The access of meaning for lexically ambiguous words has long been a focus for research (e.g., Conrad, 1974; Schvaneveldt, Meyer, \& Becker, 1976). Current evidence (Seidenberg, Tanenhaus, Leiman, \& Bienkowski, 1982; Swinney, 1979; Tanenhaus, Leiman, \& Seidenberg, 1979) strongly suggests that multiple meanings of a lexically ambiguous word are accessed when such a word is encountered, even when context makes it clear which sense is appropriate. If multiple access occurs, then it may make processing more difficult by increasing the difficulty of lexical access or by increasing the difficulty of integration following lexical access. To determine whether readers look longer at ambiguous words, we asked subjects to read sentences such as these:

He saw the boxer (puppy) was barking at the cat.

He put the straw (wheat) in the barn for the cows.

Each sentence contained either an ambiguous noun or an unambiguous control word (in parentheses in the examples). The ambiguous word and its matched control were equated for frequency and length. The control word (and subsequent sentence context for the ambiguous word) always corresponded to the less dominant meaning of the two senses for the ambiguous word. This was done intentionally because in prior research there has been evidence of clear increases in fixation time when the disambiguating information was encountered (Carpenter \& Daneman, 1981; Frazier \& Rayner, 1982). We examined fixation duration not only on the target words themselves as a function of ambiguity, but also on the disambiguating information which followed.

\section{EXPERIMENT 1}

In Experiment 1, we examined the effect of word frequency, verb complexity, and lexical ambiguity on fixation times during reading. If these factors cause immediate processing difficulty, we should find an increased time spent fixating the appropriate target words. This increased time might reflect an increase in lexical access time, an increase in postaccess integration time, or both. The dependent variables in the study were first fixation duration and gaze duration. First fixation duration is the duration of the first fixation on a given target word. If a subject made only one fixation on the target word, that value was entered into the mean score. If a subject made more than one fixation on a target word (this occurred on $21 \%$ of the trials), only the first fixation duration was used to compute the mean. Gaze duration, on the other hand, is the sum of all of the fixations made on a target word prior to any movement away from the target word.
Although analyses on both measures are reported, they should not be interpreted as independent pieces of evidence. The gaze duration on a word includes the first fixation duration as well as the durations of subsequent consecutive fixations on the word. As a result, the gaze duration measure tends to be correlated with the first fixation measure. Both measures are reported because they may reflect different aspects of processing. The gaze duration measure reflects all the processing required before the reader moves his/her eyes away from the word; this presumably includes lexical access and may include various postaccess integrative processes (Just \& Carpenter, 1980). Inhoff (1984) suggested that the first fixation measure is a purer measure of lexical access processes. Thus, it is important to report this measure; it is possible that lexical access effects might appear in the first fixation measure but not in the gaze measure because the latter may reflect postlexical access processes as well as lexical access processes.

We examined the first fixation duration and the gaze duration on the word fixated immediately before the target and the word fixated immediately after, as well as on the target word itself.

\section{Method}

\section{Subjects}

Sixteen members of the University of Massachusetts community were paid to participate in the study. All had been in prior eyetracking experiments, had normal uncorrected vision, and were naive with respect to the purposes of the study.

\section{Procedure}

When a subject arrived for an experiment, a bite bar was prepared which served to eliminate head movements, and the eye tracking system was calibrated for the subject. This initial calibration process took approximately $5 \mathrm{~min}$. Then the procedure was explained to the subject. The subject was told that the experiment dealt with where readers look during reading. He/she was told to read each sentence for comprehension and that he/she would periodically be asked to release the bite bar and to report the sentence (verbatim or paraphrased) to the experimenter. The subject was encouraged to read as he/she would normally, including rereading the sentence if desired.

At the start of each trial, a left and a right fixation cross were displayed. The subject was instructed to look at the left fixation cross, which marked the position of the first letter of the sentence. Once the subject had fixated the left-hand cross, the experimenter presented the sentence. After reading the sentence, the subject pushed a button, which erased the sentence from the screen. On $25 \%$ of the sentences, the experimenter asked the subject to release the bite bar to report the sentence just read; sentences to be reported were selected randomly. Subjects had no difficulty in reporting the sentences to the experimenter.

\section{Apparatus}

Eye movements were recorded by a Stanford Research Institute Dual Purkinje Eyetracker. Viewing was binocular, with eye location recorded from the right eye. The eyetracking system was interfaced with a Hewlett-Packard $2100 \mathrm{~A}$ computer, which ran the experiment. The position of the subject's eye was sampled every millisecond by the computer and was averaged over four consecutive samples. The horizontal position of each sample was compared with the value from the previous sample to determine whether the eye was fixated or moving. The eyetracker has a resolution of $10^{\prime}$ 
of arc, and the sentences were presented extending up to 42 characters on a single line.

The text was presented on a Hewlett-Packard 1300-A cathode ray tube (CRT), which was also interfaced with the computer. The subject's eyes were $46 \mathrm{~cm}$ from the CRT, and three characters equaled $1^{\circ}$ of visual angle. The characters were presented in lowercase (except for the first letter of the sentence) and were made up from a $5 \times 7$ dot matrix. The CRT was covered with a dark theater gel so that the characters appeared very clear to the subjects.

\section{Materials}

A set of eight word pairs was constructed for each of the five types of lexical complexity to be investigated. One member of each pair came from the category of interest (ambiguous, factive, decomposable causative, negative, low-frequency). The other member was a control word closely matched for length in letters, number of syllables, and frequency using the Kucera-Francis (1967) norms (with the exception of the low-frequency words, which were always matched with high-frequency words of the same length). Mean length, number of syllables, and frequency for each word-pair set are given in Table 1.

For each word pair, two sentence frames were constructed. Each member of the word pair fit smoothly into each sentence frame. Sentences were no longer than 42 characters (including spaces). The target words never appeared as the first or last word of the sentence. Two materials sets were created, each containing six practice sentences followed by all 80 sentence frames. In one materials set, a given lexically complex item was assigned to one of its sentence frames and its control word was assigned to the other. This assignment was reversed in the other materials set. A given subject saw only one of the materials sets. Principles of construction of the word lists are given below. A complete list of the stimulus sentences is given in Appendix A.

Frequency. Eight nouns with a frequency of 10 or less (Kucera \& Francis, 1967) were chosen. These were paired with nouns of similar meaning with frequencies of 35 or greater.

Causative. A verb was considered to be causative if (1) its meaning took the form "cause to X," and (2) the object of the verb, when used in a positive sentence, underwent some change. For example, the verb frightened is causative because (1) it means "caused to be afraid," and (2) in the sentence "The policeman frightened the little girl," its object, "the little girl," undergoes a change from being unafraid to being afraid. Each causative verb was paired with a noncausative control verb.

Factive. A factive verb is one that presupposes the truth of its complement. Eight verbs that met this basic test and eight matched control verbs were chosen. Each verb could be placed in its active form in a sentence of the type noun phrase verb(ed) that $X$, where $X$ was a sentential complement. When the sentence frame contained one of the factive verbs, it presupposed the truth of the sentential

Table 1

Mean Number of Letters, Number of Syllables, and Frequency of Word Pairs Used in Experiment 1

\begin{tabular}{lccc}
\hline & Letters & Syllables & Frequency \\
\hline Low-Frequency & 6.3 & 1.9 & 5.1 \\
High-Frequency & 6.3 & 2.0 & 122.3 \\
Causative & 7.9 & 1.9 & 29.1 \\
Control & 8.1 & 2.3 & 29.4 \\
Factive & 8.1 & 2.5 & 35.3 \\
Control & 8.3 & 2.5 & 35.6 \\
Negative & 8.0 & 2.3 & 21.9 \\
Control & 8.0 & 2.3 & 21.6 \\
Ambiguous & 5.0 & 1.4 & 17.6 \\
Unambiguous & 4.9 & 1.5 & 17.6 \\
\hline
\end{tabular}

complement that followed; when it contained one of the control verbs, there was no presupposition about the truth of the sentential complement.

There has been some discussion in the linguistics literature concerning the degree to which the set of factive verbs is a homogeneous set (Karttunen, 1971; Kiparsky \& Kirparsky, 1971; Lakoff, 1973). A number of additional tests for factivity have now been proposed, and few verbs meet all of the tests. Three of the factives used in this study (regret, forget, resent) meet all of the additional tests proposed and are classified by Karttunen as true factives. The other five meet some of the additional tests; three of these (notice, discover, realize) are classified by Karttunen as semifactives. It is important to emphasize that all of the factive verbs chosen for this study meet the basic presupposition test when they are used as affirmative, active verbs, as in sentences of the type given above.

Negative. A verb was considered to be negative if it could be reexpressed as "not $X$," where $X$ was a verb that intuitively had a positive meaning. Eight negative verbs were chosen and were matched with eight positive verbs as controls.

Ambiguous. Eight ambiguous words with two noun meanings were chosen. Each was paired with an unambiguous control word that was similar in meaning to the less likely meaning of the ambiguous word. Sentence frames were constructed such that the ambiguous word was ambiguous when encountered; disambiguating information appeared at the end of the sentence. The intended meaning was always the less likely meaning for the ambiguous word. This meaning was determined using ratings collected by Gorfein, Viviani, and Leddo (1982) and ratings we collected at the University of Massachusetts. The mean rating for the less likely meaning for the set of ambiguous words used was 24 (the mean percentage of subjects giving this meaning for the word when it was presented in a rating task).

\section{Results and Discussion}

Fixations on the target word were tallied, as well as fixations on the word fixated immediately before the target word (labeled position T -1 ) and the one fixated immediately after (labeled $T+1$ ). If the target word was not directly fixated, the closest fixation within five character spaces to the left of the target word or one space to the right was counted as the fixation during which the target word was processed. Occasionally, a sentence was presented before the subject's eyes had moved to fixate the left fixation cross. As a result, the first fixation fell on the target word or on a word following the target word, and the subject had to regress to read the whole sentence. These trials were dropped from the analysis. A total of $4.5 \%$ of the trials yielded unusable data due to track losses, lack of a fixation near the target word, or the first fixation's falling on or after the target word.

For each factor, analyses of first fixation duration and gaze duration are reported for the target word, the last word fixated before the target word (position $\mathrm{T}-1$ ), and the first word fixated after the target word (position $\mathrm{T}+1$ ). If complexity does affect word processing, then more time should be spent on the complex target words, but there should be no difference in the time spent on the word fixated at position $T-1$. If integration processes are affected by complexity, the word fixated at position $T+1$ may also have longer fixations when it follows the complex target item. Means for these measures for each set of target words are presented in Table 2. 
Table 2

Mean First Fixation Durations and Gaze Durations (in Milliseconds) Preceding, On, and Following Target Word in Experiment 1

\begin{tabular}{|c|c|c|c|c|c|c|}
\hline & \multicolumn{3}{|c|}{ First Fixation } & \multicolumn{3}{|c|}{ Gaze } \\
\hline & $\overline{T-1}$ & Target & $T+1$ & $T-1$ & Target & $T+1$ \\
\hline Low-Frequency & 213 & 262 & 258 & 263 & 330 & 296 \\
\hline High-Frequency & 221 & 225 & 248 & 258 & 243 & 259 \\
\hline Causative & 238 & 247 & 246 & 292 & 307 & 302 \\
\hline Control & 232 & 254 & 245 & 299 & 294 & 292 \\
\hline Factive & 244 & 252 & 213 & 326 & 289 & 217 \\
\hline Control & 255 & 250 & 219 & 330 & 308 & 226 \\
\hline Negative & 225 & 257 & 272 & 283 & 308 & 369 \\
\hline Control & 228 & 252 & 251 & 274 & 299 & 326 \\
\hline Ambiguous & 221 & 218 & 225 & 234 & 251 & 249 \\
\hline Control & 206 & 220 & 224 & 221 & 251 & 243 \\
\hline
\end{tabular}

At each position, two ANOVAs were conducted, one based on subject variability $\left(F_{1}\right)$ and one based on item variability $\left(F_{2}\right)$.

\section{Frequency}

As expected, subjects spent significantly longer on both the first fixation on the infrequent word $\left[F_{1}(1,15)=\right.$ $19.17, M S \mathrm{e}=577, p<.001 ; F_{2}(1,15)=24.29, M S \mathrm{~S}$ $=388, p<.001]$ and the gaze on the infrequent word $\left[\mathrm{F}_{1}(1,15)=40.29, M S \mathrm{e}=1,492, p<.0001 ; F_{2}(1,15)\right.$ $=37.58, M S e=1,423, p<.0001]$. The mean gaze duration was also longer at position $\mathrm{T}+1$ in the infrequent condition $\left[F_{1}(1,15)=7.64, M S e=1,443, p<.02\right.$; $\left.F_{2}(1,15)=12.46, M S e=900, p<.004\right]$; the mean first fixation durations at position $\mathrm{T}+1$ did not differ. There were no differences in time spent on position $T-1$.

The longer times on the infrequent targets are consistent with the findings of earlier studies (e.g., Inhoff, 1984; Just \& Carpenter, 1980; Rayner, 1977). A number of hypotheses can be developed to account for this effect. Infrequent words may be more difficult to access in the lexicon. In addition, once accessed, infrequent words may be more difficult to integrate with prior context. The fact that gaze duration at position $\mathrm{T}+1$ was also lengthened for infrequent words lends support to this second hypothesis.

A hypothesis that can be eliminated is that the infrequent target words contained letters and letter combinations that are infrequent in English and hence were more slowly encoded. Letter and letter combination frequencies were tallied for the frequent and infrequent target words, using the Mayzner and Tresselt norms (1965a, 1965b). Taken singly, the letters in the infrequent target words had a higher mean frequency than those in the frequent target words (206 vs. 169, tallying letter frequency by position in the word; 5,714 vs. 5,037 , tallying total letter frequency across positions). There was little difference in the mean two-letter (digram) frequency counts for the infrequent versus frequent targets ( $25 \mathrm{vs.27}$, tallying by position; 359 vs. 330 , tallying total frequency). The infrequent words did have less frequent three-letter com- binations than the frequent target words ( 2.1 vs. 3.9 , tallying by position; 20 vs. 28 , tallying total frequency). For word pairs in which these trigram frequencies were reversed, however, the word frequency effect was still observed.

\section{Verb Complexity}

There was no effect of causative verbs in the analyses of first fixation or gaze duration (all $F \mathrm{~s}<1$ ) at any position.

Subjects tended to spend more time on the nonfactive control verbs than on the factive verbs. This effect reached significance in the subject analysis of gaze duration but was not significant in the item analysis $\left[F_{1}(1,15)=4.91\right.$, $M S \mathrm{e}=596, p<.05 ; F_{2}(1,15)=1.76, M S \mathrm{e}=1,364$, p > .20]; it was also not significant in the first fixation analysis. There were no significant differences at positions $T-1$ and $T+1$. The effect on the target words was a weak one, and it was opposite to that predicted by the complexity hypothesis; the complexity hypothesis predicted that fixation times would be longer on the factive verbs. Thus the data provide no support for the claim that the complexity of the factive representation results in increased processing time. Further converging evidence against the complexity hypothesis was provided by Inhoff (1985), who found no difference in fixation times on factive verbs versus nonfactive controls.

Finally, there was no effect of negative verb on time spent on the target or on position $\mathrm{T}-1$. Gazes at position $T+1$ tended to be longer when they followed a negative verb. This effect was significant in the subject analysis but not in the item analysis $\left[F_{1}(1,15)=5.39, M S\right.$ e $=$ $2,624, p<.04 ; F_{2}(1,15)=2.81, M S e=2,590$, $p<.12$ ). This effect is unlikely to reflect lexical access difficulties, but may reflect increased time needed to integrate the negative verb with the sentence context.

The results for causative, factive, and negative verbs provide no evidence that complexity of lexical representation had any effect on either the first fixation duration or gaze duration on the target verb. We assume that lexical access for the target word is accomplished while the reader fixates the target word. Thus we have no evidence here that complexity of lexical representation had any effect on lexical access for the three types of verbs tested.

\section{Lexical Ambiguity}

There was no effect of ambiguity within the analyses of gaze duration or first fixation duration at any position (all $F \mathrm{~s}<1$ ). Further analyses of the stimulus items, however, suggested an additional factor that might have masked any effects in the data. The less likely meanings for the ambiguous lexical items varied in probability from fairly likely (generated by $48 \%$ of subjects in a norming task) to extremely unlikely (generated by $1 \%$ of subjects in a norming task). Recent studies strongly suggest that in contexts such as those used here, all meanings of an ambiguous word are accessed initially (Seidenberg et al., 1982; Swinney, 1979); this includes the low-frequency 
meanings (Onifer \& Swinney, 1981; Yates, 1978). There is some indication, however, that low-frequency meanings may be delayed in access (Simpson \& Burgess, 1982) or otherwise less available to higher level processing stages (Hogaboam \& Perfetti, 1975; Simpson, 1981, 1984). It may be the case that two meanings of an ambiguous word cause processing difficulty only when the meanings are fairly equally likely (i.e., when the ambiguous item is equibiased). When one meaning is highly likely (the item is non-equibiased) and there is no prior biasing context, the less likely meaning(s) may not affect processing. If this is the case, the lack of effect for the ambiguous words may be due to the presence of a number of non-equibiased lexical items among the stimuli.

In a post hoc test of this hypothesis, the eight ambiguous words were divided into two groups according to degree of equibias. The less likely meanings for the four equibiased items had a mean probability of .38 ; the less likely meanings for the four non-equibiased items had a mean probability of .11 . The mean gaze durations for these groups were $269 \mathrm{msec}$ for the equibiased words, $253 \mathrm{msec}$ for their controls, $236 \mathrm{msec}$ for the nonequibiased words, and $254 \mathrm{msec}$ for their controls. Although the number of items in each group is small, the pattern of means is consistent with the hypothesis. Experiment 2 provided a further test of this hypothesis, using a larger set of equibiased and non-equibiased words.

Two additional analyses were conducted to examine the effect of ambiguity on processing beyond the first encounter with the target word. The first analysis examined the total time spent looking at the target word; this measure consists of the gaze duration on the target word plus any additional time spent looking at the word during regressions and rereading. Subjects spent an average of $314 \mathrm{msec}$ on the ambiguous targets and $262 \mathrm{msec}$ on their controls. The difference between these means was significant $\left[F_{1}(1,15)=8.48, p<.02, M S \mathrm{e}=2,570\right.$; $\left.F_{2}(1,15)=15.55, p<.002, M S e=1,261\right]$.

The second additional analysis examined the time spent reading the disambiguating information in the sentence. For each sentence frame, the disambiguating region was identified. All fixations that occurred after this disambiguating region was first fixated were summed (including regressions to earlier parts of the sentence) and the sum was divided by the number of characters in the disambiguating region. This yielded a measure of milliseconds per character spent in disambiguating the target word. Subjects spent $82 \mathrm{msec}$ per character on the disambiguating region when the target word was ambiguous, and $64 \mathrm{msec}$ per character when it was unambiguous. The difference in these means was significant $\left[F_{1}(1,15)=10.31, p<.006, M S e=262 ; F_{2}(1,15)=\right.$ $17.98, p<.001, M S e=113]$.

Our finding of an effect of ambiguity in the disambiguating region was predicted by prior research. Swinney (1979) and Seidenberg et al. (1982) found evidence that, although both meanings of an ambiguous word are accessed initially, one meaning is selected within $200 \mathrm{msec}$ even in the absence of a disambiguating con- text. In the sentences used here, such a selection could be expected to take place before the reader encountered the disambiguating information at the end of the sentence. Presumably, readers tended to select the most likely meaning of the ambiguous word. Since the disambiguating information was congruent with the less likely meaning of the ambiguous word, a time-consuming reanalysis would be required for comprehension.

\section{EXPERIMENT 2}

Two sets of ambiguous lexical items were used in this experiment: equibiased and non-equibiased. As in Experiment 1, each was paired with an appropriate control word. The experiment tested the hypothesis that processing is more difficult for equibiased ambiguous words than for unambiguous controls, but not more difficult for nonequibiased ambiguous words than for unambiguous controls. This hypothesis predicts that mean fixation times for the equibiased items will be longer than those for their controls, but that times for the non-equibiased items will not differ from those for their controls.

Time spent in the disambiguating region should be longer, as it was in Experiment 1, for sentence frames containing ambiguous items than for those containing control items. Ease of processing the disambiguating information may differ for equibiased and non-equibiased ambiguous words. As in Experiment 1, the sentence frames were written so that the disambiguating information was congruent with the less likely meaning of the ambiguous word. This meaning had an extremely low probability for the non-equibiased items. If the likelihood of selecting this meaning is a function of its probability (Simpson, 1981), these items should show extremely long reading times, compared with those for the equibiased items, in the disambiguating region.

\section{Subjects \\ Method \\ Thirty-two members of the University of Massachusetts commu- nity were paid to participate in the study.}

\section{Procedure and Apparatus}

The procedure and apparatus were the same as in Experiment 1.

\section{Materials}

Nine equibiased and nine non-equibiased ambiguous lexical items were chosen, using the norms of Gorfein et al. (1982), Geis and Winograd (1974), and ratings collected locally. The dominant meanings for the equibiased items had a probability range of .47-.67, with a mean of .58 (the range extends below .50 because a few words had more than two meanings); the nondominant meanings had a range of .33-.49, with a mean of .40 . The dominant meanings for the non-equibiased items had a probability range of .78-.98, with a mean of .87; the nondominant meanings had a range of $.02-.22$, with a mean of .13 . Each ambiguous item was paired with an unambiguous control word closely matched for letter length, number of syllables, and frequency. Mean frequencies for the equibiased ambiguous items and their controls were 32.6 and 29.4; for the non-equibiased items and their controls, 31.6 and 30.6.

For each pair, two sentence frames were constructed, as in Experiment 1 . The ambiguous items were ambiguous when encountered and were disambiguated at the end of the sentence. The intended meaning was always the less likely meaning listed in the 
norms. (The norms present ratings for only two meanings of each ambiguous word, although some words have additional meanings.) A complete list of the stimulus sentences is given in Appendix B.

The stimuli were arranged in two materials sets. Both sentence frames for each word pair appeared in both sets. In one materials set, an ambiguous item was assigned to one of its sentence frames and its control word was assigned to the other. The assignment pattern was reversed in the other materials set. A given subject saw only one of the materials sets. Twenty filler sentences were included in the set, including four practice items inserted at the beginning.

\section{Results and Discussion}

The data were scored as in Experiment 1. A total of $3.7 \%$ of the trials yielded unusable data. Three sets of means are given in Table 3: gaze durations on the target word and at positions $T-1$ and $T+1$, first fixation durations at the three positions, and time spent on the disambiguating information.

As originally predicted, subjects spent extra time looking at the ambiguous target items when two meanings for the ambiguous item were fairly equally likely. This was not the case for ambiguous words for which one meaning was highly likely. In the analysis of gaze durations on the target word, neither main effect was significant, but the interaction of word type and bias was significant $\left[F_{1}(1,31)=4.67, p<.037, M S \mathrm{e}=392 ; F_{2}(1,34)=\right.$ $4.75, p<.035, M S e=392]$. This interaction is due to the longer times on the equibiased ambiguous target items. Within each bias type, $t$ tests indicated that the mean gaze duration for the equibiased ambiguous targets was significantly longer than that for their controls $[t(31)=2.64$, $p<.02]$; there was no significant difference between the means for the non-equibiased targets and their controls $[t(31)=-.58]$. Although the pattern of first fixation means was simiar to that of gaze duration means, the interaction was not significant in the first fixation analysis $\left[F_{1}(1,31)=2.31, p<.14, M S \mathrm{e}=433 ; F_{2}(1,34)=\right.$ $2.91, p<.10, M S \mathrm{e}=280]$.

One way to account for the interaction pattern would be to claim that both likely meanings are accessed for the equibiased ambiguous targets, whereas only the dominant meaning is accessed for the non-equibiased targets. If this is the case, then there are at least two possible reasons for the additional processing time for the equibiased items. First, lexical access may take longer when two separate meanings for a word must be accessed in the lexicon. Second, following lexical access, the process of integrating the target word with the preceding context may take longer when this process has two possible meanings available as input. This account depends on the assumption that only one meaning is accessed for the non-equibiased ambiguous targets. Research using a cross-modality priming technique, however, suggests that even the low-dominant meanings of an ambiguous word are initially accessed when such a word is encountered (Onifer \& Swinney, 1981).

Perhaps a more reasonable account of the interaction would claim that meaning dominance affects the postaccess selection and integration processes. Recent research (Swinney, 1979; Seidenberg et al., 1982) strongly suggests that although all meanings of an ambiguous word are initially accessed, one meaning is quickly selected even in the absence of disambiguating context. This selection process may be more difficult for the equibiased ambiguous targets, for which the reader must decide between two equally likely meanings. The selection may be much easier, and hence quicker, for the non-equibiased targets, for which one meaning predominates.

Another possible account of the interaction pattern focuses on the appropriateness of the control words used for the equibiased ambiguous targets. If each ambiguous word is actually represented by two separate entries in the lexicon, then the frequency count for that word from the Kučra-Francis norms is the sum of the frequencies of each entry. One could thus argue that the control words used were too high in frequency. It might have been more appropriate to use control words that were equal in frequency to the frequency of the more dominant meaning of the ambiguous words. We tried to approximate this approach by reselecting control words from among the complete set used in Experiment 2 . In this reanalysis, we

Table 3

Mean First Fixation Durations and Gaze Durations (in Milliseconds) on Target Words and Mean Time (in Milliseconds per Character) Spent on the Disambiguating Region in Experiment 2

\begin{tabular}{|c|c|c|c|c|c|c|}
\hline & \multicolumn{2}{|c|}{$\mathrm{T}-1$} & \multicolumn{2}{|c|}{ Target } & \multicolumn{2}{|c|}{$T+1$} \\
\hline & Ambiguous & Control & Ambiguous & Control & Ambiguous & Control \\
\hline \multicolumn{7}{|c|}{ Gaze Duration on Target Words } \\
\hline Equibiased & 246 & 248 & 275 & 258 & 269 & 251 \\
\hline Non-Equibiased & 249 & 245 & 260 & 263 & 266 & 256 \\
\hline \multicolumn{7}{|c|}{ First Fixation Duration on Target Words } \\
\hline Equibiased & 227 & 222 & 237 & 229 & 244 & 232 \\
\hline Non-Equibiased & 221 & 223 & 227 & 230 & 238 & 233 \\
\hline \multicolumn{7}{|c|}{ Time Spent on Disambiguating Region } \\
\hline & & \multicolumn{2}{|c|}{ Ambiguous } & Contro & & \\
\hline & $\begin{array}{l}\text { Equibiase } \\
\text { Non-Equi }\end{array}$ & iased & $\begin{array}{l}76 \\
82\end{array}$ & $\begin{array}{l}64 \\
60\end{array}$ & & \\
\hline
\end{tabular}


created an adjusted frequency for each equibiased ambiguous word by multiplying its original frequency by the proportion of subjects giving the more dominant meaning. We took this figure as an estimate of the frequency of the dominant meaning for the word. We then paired each equibiased ambiguous word with a new control word that had a frequency equal to or less than that of the adjusted frequency for the ambiguous word. The resulting mean adjusted frequency for the equibiased ambiguous words was 18; the mean frequency of the newly selected control words was 14 . The mean gaze duration for the new set of control words was $265 \mathrm{msec}$. Thus, the mean gaze duration of the new control set was still $10 \mathrm{msec}$ shorter than that of the equibiased ambiguous set, even though the control words were now less frequent, on average, than their ambiguous counterparts. Although it may be informative in future studies to include additional control words having the appropriate adjusted frequencies, we feel the current results do not provide strong support for the adjusted frequency account.

An analysis of the mean gaze durations and first fixation durations at position $\mathrm{T}-1$ revealed no effects (all $F \mathrm{~s}<1)$. In the analysis of position $\mathrm{T}+1$, only the effect of ambiguity approached significance [gaze: $F_{1}(1,31)=$ $3.36, M S e=1,923, p<.08 ; F_{2}(1,34)=7.77, M S e=$ $440, p<.01$; first fixation: $F_{1}(1,31)=3.13, M S \mathrm{e}=$ $\left.803, p<.09 ; F_{2}(1,34)=3.60, M S e=446, p<.07\right]$. This effect reflects the fact that the $T+1$ fixation frequently fell in the disambiguating region.

In the analysis of the disambiguating region, we found a main effect of ambiguity, with subjects spending longer on the ambiguous sentences than on the controls $\left[F_{1}(1,31)\right.$ $=33.86, p<.0001, M S \mathrm{e}=268 ; F_{2}(1,34)=16.15$, $p<.0006, M S e=299$ ]. The interaction pattern was as predicted, with subjects spending even longer on the nonequibiased sentences. This pattern was significant in the subject analysis $\left[F_{1}(1,31)=7.24, p<.011, M S e=112\right]$ but not in the item analysis $\left[F_{2}(1,34)=1.67, p<.21\right.$, $M S e=299]$.

The analysis of the disambiguating region indicates that although the equibiased ambiguous items required additional processing time when they were first encountered, the non-equibiased ambiguous items required more time when they were finally disambiguated. There are two possible complementary reasons for this finding. First, it is reasonable to assume that the postaccess selection process virtually always selected the dominant meaning for the non-equibiased ambiguous items. Because this meaning was always incongruent with the disambiguating information, a time-consuming reinterpretation was required when the disambiguating information was encountered. Such a reinterpretation was probably required on almost all of the trials involving non-equibiased items. In contrast, if subjects randomly selected one of two equally likely meanings for the equibiased ambiguous items, they were likely to select the inappropriate meaning on only about half the trials. Thus, fewer time-consuming reinterpretations were required for the equibiased ambiguous target sentences. Second, when a reinterpretation was required, the speed with which the alternative meaning was reaccessed may have been a function of its likelihood. The alternative meanings for the non-equibiased ambiguous items were much less likely than those for the equibiased items, and may thus have taken longer to reaccess when a reinterpretation was required.

\section{GENERAL DISCUSSION}

The pattern of results from the various conditions in which lexical complexity was varied was quite straightforward. First, there was a strong effect of word frequency: low-frequency words matched on word length yielded longer fixation times than did high-frequency words. In addition, the presence of a low-frequency word in a sentence increased the gaze duration on the next word fixated in the sentence. Second, there was no effect of verb complexity on fixation time on a word. Finally, fixation time on ambiguous words yielded an interesting pattern. When the ambiguous word had a highly dominant interpretation, its fixation time did not differ from the fixation time on a control word that was matched in word frequency and was synonymous with the less dominant meaning. On the other hand, when the ambiguous word had two equibiased interpretations, subjects looked at it significantly longer than at a matched control word. However, in the latter case, when they reached the disambiguating information their reading was not disrupted as much as in the former case, when the disambiguating information was consistent with the less frequent meaning of a word with a highly dominant interpretation.

Although word frequency effects in reading have been demonstrated before (Inhoff, 1984; Just \& Carpenter, 1980; Rayner, 1977), in these studies, word length was not controlled (Kliegl et al., 1982). In our experiment, word length was controlled, and we still obtained a 37msec effect on first fixation duration and an 87-msec effect on gaze duration. The results reported here for word frequency are consistent with other recent research in our laboratory (Inhoff \& Rayner, 1986). Inhoff and Rayner also varied word frequency, controlling word length as we did, and their results were comparable to ours. However, they also varied whether or not their subjects had preview information about the high- or low-frequency word before they fixated on it. Although the effect of frequency was smaller with no preview, gaze durations were longer on low-frequency words than on high-frequency words even when no preview information was available. Thus, much of the difference in fixation time between high- and low-frequency words was apparently due to processing associated with accessing or integrating the. word when it was directly fixated.

Balota and Chumbley $(1984,1985$; Chumbley \& Balota, 1984) argued that much of the word frequency effect in lexical decision and pronunciation tasks can be attributed to postaccess decision or production stages. They argued that although word frequency may also affect the speed 
of lexical access, this effect is more modest than might be expected. It is unlikely that our reading task involved the postaccess stages associated with the lexical decision or pronunciation tasks used by Balota and Chumbley; however, our task should involve a sentence integration stage, which is another postaccess stage likely to be affected by word frequency. An effect at the integration stage could occur for at least two reasons. First, our sentence frames may have been unintentionally biased to fit better with the frequent target than with the infrequent target. An examination of the sentences, however, reveals no obvious bias in the context preceding the target word (i.e., the adjective). A second, more likely, reason is that the meanings of infrequent words tend to be represented in a less complete or well-elaborated form than the meanings of more frequent words. As a result, it is harder to integrate the meanings of infrequent words with the preceding sentence context.

The finding that verb complexity did not influence fixation time on the verb is consistent with Cutler's (1983) results using a phoneme monitoring task. These results can be taken to indicate that the complexity of a word's meaning representation does not affect lexical access time. Alternatively, these results could indicate the need for modifications in the theory of meaning representation that produces the complexity predictions (J. A. Fodor et al., 1980). These findings do not imply, however, that all word meanings, once accessed, are equally easy to integrate into the sentence context. The tendency for fixations to be longer following a negative verb argues against this view, as does the earlier literature showing increased difficulty in processing sentences containing negatives. Complexity per se, however, may not be the source of integration difficulty. Rather, the presence of certain specific elements (e.g., a negative) may result in increased integration time.

Perhaps the most interesting results of our experiments, because such effects have not been previously investigated, are those related to the processing of ambiguous words. The pattern of gaze durations on our target words suggests that low-frequency meanings do not have the same status as high-frequency meanings in the initial processing of an ambiguous word. Although all meanings of a word may be accessed regardless of likelihood (Onifer \& Swinney, 1981), these meanings may not all be equally available to the processing stages following lexical access (Hogaboam \& Perfetti, 1975; Simpson, 1984; Simpson \& Burgess, 1982). It may be the case, for example, that equally frequent meanings tend to become available to postaccess processes at the same time, thus forcing the reader to make a time-consuming selection. Infrequent meanings, on the other hand, may become available after postaccess processes have begun working on the dominant meaning, and thus may be ignored by these postaccess processes. Further research is needed to resolve these issues.
Our finding of a general pattern of differential fixation times as a function of word frequency and lexical ambiguity is consistent with the idea that eye fixation times reflect moment-to-moment processing activities associated with comprehending words in text (Just \& Carpenter, 1980; Rayner, 1977, 1978). We pointed out at the beginning of this article that fixation times on words can be affected by a number of factors. In the present experiments, we have demonstrated that factors associated with verb complexity do not influence fixation times, whereas word frequency and lexical ambiguity do. Although we cannot at this point differentiate between (or localize the effect solely to) lexical-access or sentence-integration processes, the results suggest that both types of processes may be reflected in fixation times on words. Thus, fixation times on a given word are a good indication of the ease or difficulty experienced by the reader in understanding that word.

\section{REFERENCES}

Balota, D. A., \& Chumbley, J. I. (1984). Are lexical decisions a good measure of lexical access? The role of word frequency in the neglected decision stage. Journal of Experimental Psychology: Human Perception \& Performance, 10, 340-357.

Balota, D. A., Chumbley, J. I. (1985). The locus of word-frequency effects in the pronunciation task: Lexical access and/or production? Journal of Memory \& Language, 24, 89-106.

Balota, D. A., Pollatsek, A., \& Rayner, K. (1985). The interaction of contextual constraints and parafoveal visual information in reading. Cognitive Psychology, 17, 364-390.

Bierwisch, M. (1970). Semantics. In J. Lyons (Ed.), New horizons in linguistics. London: Penguin.

Carpenter, P. A., \& Daneman, M. (1981). Lexical retrieval and error recovery in reading: A model based on eye fixations. Journal of Verbal Leaming \& Verbal Behavior, 20, 137-160.

CARPENTER, P. A., \& JUST, M. A. (1975). Sentence comprehension: A psycholinguistic processing model of verification. Psychological Review, 82, 45-73.

Chumbley, J. I., \& Balota, D. A. (1984). A word's meaning affects the decision in lexical decision. Memory \& Cognition, 12, 590-606.

ClaRK, H., \& ChaSe, W. (1972). On the process of comparing sentences against pictures. Cognitive Psychology, 3, 472-517.

Clark, H., \& Clark, E. (1977). Psychology and language. New York: Harcourt Brace Jovanovich.

ConRad, C. (1974). Context effects in sentence comprehension: A study of the subjective lexicon. Memory \& Cognition, 2, 130-138.

Cutler, A. (1983). Lexical complexity and sentence processing. In G. B. Flores d'Arcais and R. J. Jarvella (Eds.), The processes of language understanding. New York: Wiley.

EhrLich, K., \& RAYNer, K. (1983). Pronoun assignment and semantic integration during reading: Eye movements and immediacy of processing. Journal of Verbal Learning \& Verbal Behavior, 22, 75-87.

EHRLICH, S. F., \& RAYNER, K. (1981). Contextual effects on word perception and eye movements during reading. Joumal of Verbal Leaming \& Verbal Behavior, 20, 641-655.

Fodor, J. A., Garrett, M., Walker, E., \& PARKes, C. (1980). Against definitions. Cognition, 8, 263-367.

Fodor, J. D., Fodor, J. A., \& Garrett, M. (1975). The psychological unreality of semantic representations. Linguistic Inquiry, 6 515-531.

FRAZIER, L., \& RAYNER, K. (1982). Making and correcting errors during sentence comprehension: Eye movements in the analysis of structurally ambiguous sentences. Cognitive Psychology, 14, 178-210. 
GeIs, M., \& WinogRad, E. (1974). Norms of semantic encoding variability for fifty homographs. Bulletin of the Psychonomic Society, 3 , 429-431.

Gorfein, D., Viviani, J., \& LedDo, J. (1982). Norms as a tool for the study of homography. Memory \& Cognition, 10, 503-509.

Hogaboam, T., \& Perfetti, C. (1975). Lexical ambiguity and sentence comprehension. Joumal of Verbal Learning \& Verbal Behavior, 14, 265-274.

Holmes, V. M., \& O'RegaN, J. K. (1981). Eye fixation patterns during the reading of relative-clause sentences. Joumal of Verbal Learning \& Verbal Behavior, 20, 417-430.

INHOFF, A. W. (1984). Two stages of word processing during eye fixations in the reading of prose. Journal of Verbal Learning \& Verbal Behavior, 23, 612-624.

INHOFF, A. W. (1985). The effect of factivity on lexical retrieval and postlexical processes during eye fixations in reading. Journal of Psycholinguistic Research, 14, 45-56.

INHOFF, A. W., \& RAYNeR, K. (1986). Parafoveal word processing during eye fixations in reading: Effects of word frequency. Manuscript submitted for publication.

Just, M. A., \& Carpenter, P. A. (1980). A theory of reading: From eye fixations to comprehension. Psychological Review, 87, 329-354.

JUST, M. A., \& CLARK, H. (1973). Drawing inferences from the presuppositions and implications of affirmative and negative sentences. Journal of Verbal Learning \& Verbal Behavior, 12, 21-31.

KartTUNen, L. (1971). Some observations on factivity. Papers in Linguistics, 4, 55-69.

KATZ, J. (1972). Semantic theory. New York: Harper \& Row.

$\mathrm{KINTSCH}, \mathrm{W}$. (1974). The representation of meaning in memory. Hillsdale, NJ: Erlbaum.

KIPARSKY, P., \& KIPARSKY, C. (1971). Fact. In D. Steinberg \& L. Jakobovits (Eds.), Semantics (pp. 345-369). Cambridge, England: Cambridge University Press.

KLiegl, R., Olson, R. K., \& Davidson, B. J. (1982). Regression analysis as a tool for studying reading processes: Comment on Just and Carpenter's eye fixation theory. Memory \& Cognition, 10, 287-296.

KuČERA, H., \& FranCIS, W. (1967). Computational analysis of presentday American English. Providence, RI: Brown University Press.

LAKOFF, R. (1973). Review of Progress in Linguistics. Language, 49, 685-697.

MAyzNer, M., \& Tresselt, M. (1965a). Tables of single-letter and digram frequency counts for various word-length and letter-position combinations. Psychonomic Monograph Supplements, 1, 13-32.

MAYZner, M., \& TrEsSELT, M. (1965b). Tables of trigram frequency counts for various word-length and letter-position combinations. Psychonomic Monograph Supplements, 1, 33-78.

Mehler, J., Segui, J., \& Carey, P. (1978). Tails of words: Monitoring ambiguity. Journal of Verbal Learning \& Verbal Behavior, 17, 29-35.

Newman, J. E., \& Dell, G. S. (1978). The phonological nature of phoneme monitoring: A critique of some ambiguity studies. Journal of Verbal Learning \& Verbal Behavior, 17, 359-374.

Norman, D., \& RumelharT, D. (1975). Explorations in cognition. San Francisco: Freeman.

ONIFER, W., \& SWINNEY, D. (1981). Accessing lexical ambiguities during sentence comprehension: Effects of frequency of meaning and contextual bias. Memory \& Cognition, 9, 225-236.

RAYNER, K. (1975). The perceptual span and peripheral cues in reading. Cognitive Psychology, 7, 65-81.

RAYNER, K. (1977). Visual attention in reading: Eye movements reflect cognitive processes. Memory \& Cognition, 4, 443-448.

RAYNER, K. (1978). Eye movements in reading and information processing. Psychological Bulletin, 85, 618-660.

RAYNER, K. (1984). Visual selection in reading, picture perception, and visual search: A tutorial review. In H. Bouma \& D. W. Bouwhuis (Eds.), Attention and performance $X$ (pp. 67-96). Hillsdale, NJ: Erlbaum.

Rayner, K., Carlson, M., \& Frazier, L. (1983). The interaction of syntax and semantics during sentence processing: Eye movements in the analysis of semantically biased sentences. Journal of Verbal Learning \& Verbal Behavior, 22, 358-374.

Rayner, K., Slowiaczek, M. L., Clifton, C., \& Bertera,
J. H.(1983). Latency of sequential eye movements: Implications for reading. Journal of Experimental Psychology: Human Perception \& Performance, 9, 912-922.

Schank, R. (1972). Conceptual dependency: A theory of natural language understanding. Cognitive Psychology, 3, 552-631.

Schvaneveldt, R., Meyer, D., \& Becker, C. (1976). Lexical ambiguity, semantic context, and visual word recognition. Journal of Experimental Psychology: Human Perception \& Performance, 2, 243-256.

Seidenberg, M. S., Tanenhaus, M. K., Leiman, J. M., \& BIENKowsKI, M. (1982). Automatic access of the meanings of ambiguous words in context: Some limitations of knowledge-based processing. Cognitive Psychology, 14, 489-537.

Sherman, M. (1973). Bound to be easier? The negative prefix and sentence comprehension. Journal of Verbal Learning \& Verbal Behavior, 12, 76-84

Sherman, M. (1976). Adjectival negation and the comprehension of multiply negated sentences. Journal of Verbal Learning \& Verbal Behavior, 15, 143-157.

Simpson, G. (1981). Meaning dominance and semantic context in the processing of lexical ambiguity. Journal of Verbal Learning \& Verbal Behavior, 20, 120-136.

Simpson, G. (1984). Lexical ambiguity and its role in models of word recognition. Psychological Bulletin, 96, 316-340.

Simpson, G., \& BURGess, C. (1982, November). Processing lexical ambiguity: $A$ chronometric analysis. Paper presented at the annual meeting of the Psychonomic Society, Minneapolis, MN.

SwINNEY, D. A. (1979). Lexical access during sentence comprehension: (re)consideration of context effects. Journal of Verbal Learning \& Verbal Behavior, 18, 645-659.

Tanenhaus, M. K., Leiman, J. M., \& Seidenberg, M. S. (1979). Evidence for multiple stages in the processing of ambiguous words in syntactic contexts. Journal of Verbal Learning \& Verbal Behavior, $18,427-440$.

Trabasso, T., Rollins, H., \& Shaughnessy, E. (1971). Storage and verification stages in processing concepts. Cognitive Psychology, 2, 239-289.

YATES, J. (1978). Priming dominant and unusual senses of ambiguous words. Memory \& Cognition, 6, 636-643.

ZoLA, D. (1984). Redundancy and word perception during reading. Perception \& Psychophysics, 36, 277-284.

\section{APPENDIX A Sentences Used in Experiment 1}

\section{Infrequent}

(Frequent targets are enclosed in parentheses.)

1. The shiny gondola (vehicle) moved slowly.

2. The shaky gondola (vehicle) creaked loudly.

3. The large mosque (church) remained mostly empty.

4. The older mosque (church) was damaged by bombs.

5. The noisy rooster (chicken) chased the sparrows.

6. The plump rooster (chicken) found more corn to eat.

7. The sandy dunes (beach) stretched for many miles.

8. The dirty dunes (beach) became a political issue.

9. The young waiter (driver) annoyed his friends.

10. The proud waiter (driver) turned down the job.

11. The slow waltz (music) captured her attention.

12. The fast waltz (music) seemed out of place.

13. The young refugee (officer) entered the camp.

14. The angry refugee (officer) ignored the food.

15. The exhausted steward (student) left the plane.

16. The concerned steward (student) calmed the child.

\section{Causative}

(Noncausative control verbs are in parentheses.)

1. The woman cooked (tasted) the beef and potato stew. 


\section{APPENDIX A (Continued)}

2. The actor cooked (tasted) the chicken noodle soup.

3. The policeman frightened (encountered) the little girl.

4. The secretary frightened (encountered) the cat burglar.

5. He finally convinced (understood) the stubborn judge.

6. Paul never convinced (understood) the new president.

7. Richard convened (glimpsed) the committee meeting.

8. Marilyn convened (glimpsed) the first town meeting.

9. The general assembled (inherited) some loyal troops.

10. The rancher assembled (inherited) the family servants.

11. He thoughtfully reminded (examined) the old woman.

12. Robert politely reminded (examined) the elderly man.

13. The farmer killed (picked) a chicken for dinner.

14. The doctors killed (picked) the rats for the study.

15. The child cracked (scanned) the antique mirror.

16. The nurse cracked (scanned) the hand-painted plate.

Factive

(Nonfactive control verbs are in parentheses.)

1. The cook regretted (testified) that he had been lying.

2. Margaret regretted (testified) that she had been sick.

3. The maid forgot (implied) that the teacher had left.

4. Patricia forgot (implied) that she had been injured.

5. Suzanne resented (asserted) that the boy had won.

6. Michael resented (asserted) that the banker was out.

7. Charlotte realized (declared) that the bag was torn.

8. The tutor realized (declared) that the dog was dead.

9. Barbara revealed (remarked) that the girl had called.

10. Stephen revealed (remarked) that the will was a fake.

11. The dean noticed (insisted) that the toy was broken.

12. The girl noticed (insisted) that the cake was moldy.

13. Phillip discovered (mentioned) that the pond was deep.

14. The boy discovered (mentioned) that the boss was mad.

15. William disclosed (suspected) that the car was stolen.

16. Shirley disclosed (suspected) that the jewel was gone.

\section{Negative}

(Non-negative control verbs are in parentheses.)

1. The barber avoided (praised) the history teacher.

2. The lawyer avoided (praised) the ambitious salesman.

3. The doctor doubted (revised) the reporter's story.

4. The artist doubted (revised) the magazine article.

5. The captain refused (enjoyed) an elegant dinner.

6. The senator refused (enjoyed) a fattening dessert.

7. The letter distressed (implicated) the piano player.

8. The memoir distressed (implicated) the bank teller.

9. The teacher despised (rewarded) the unhappy child.

10. The dentist despised (rewarded) the newspaper editor.

11. The banker neglected (justified) his vacation plans.

12. The writer neglected (justified) the plot of his book.

13. The judge rejected (released) the lawyer's statement.

14. The baker rejected (released) the proposed prices.

15. The soldier ignored (advised) the hungry peasant.

16. The fireman ignored (advised) the town council.

\section{Ambiguous}

(Unambiguous control words are in parentheses.)

1. She thought the punch (cider) was a little sour.

2. She worried the punch (cider) would be spilled.

3. He hoped the perch (trout) would swim upstream.
4. He hoped the perch (trout) would go for the hook.

5 . He knew the yarn (tale) had been told many times.

6. He felt the yarn (tale) was too violent to tell.

7. He went to the bank (edge) of the river to read.

8. He came to the bank (edge) of the stream to rest.

9. He put the straw (wheat) in the barn for the cows.

10. He got the straw (wheat) from the old stable.

11. He thought the organ (liver) was badly infected.

12. He decided the organ (liver) could be transplanted.

13. He saw the boxer (puppy) was barking at a cat.

14. He saw the boxer (puppy) scratching its hind leg.

15. He heard the swallow (turkey) had injured a wing.

16. He heard the swallow (turkey) had just laid an egg.

APPENDIX B

Sentences Used in Experiment 2

(Unambiguous control words are enclosed in parentheses.)

Equibiased

1. He found the coach (cabin) was too hot to sleep in.

2. He found the coach (cabin) and went inside it.

3. Earlier the punch (cider) was too warm to drink.

4. We thought the punch (cider) was delicious.

5. He missed having a yard (barn) to work in.

6. John wanted a yard (barn) for his kids to play in.

7. He noticed the deed (oath) was written in Greek.

8. He felt the deed (oath) was worded very strangely.

9. He saw the beam (plug) had been poorly installed.

10. Jeff thought the beam (plug) looked damaged.

11. He wished the pitcher (catcher) had caught the ball.

12. Yesterday the pitcher (catcher) was in the big game.

13. He learned that her palm (lung) had been wounded.

14. She knew the boy's palm (lung) was injured.

15. Yesterday the volume (series) was in the library.

16. He hoped the volume (series) would be good to read.

17. He saw that the tip (lid) was badly twisted.

18. She realized that the tip (lid) was broken.

Non-Equibiased

1. He saw the perch (trout) had avoided the hook.

2. He knew the perch (trout) often swam upstream.

3. Yesterday the boxer (puppy) injured its paw.

4. We knew the boxer (puppy) was barking at night.

5 . He noticed the band (gold) on her finger.

6. He saw the band (gold) on her finger.

7. We thought the bark (leaf) had been eaten by bugs.

8. Phil knew the bark (leaf) was from the tree.

9. Last night the port (soup) had a strange flavor.

10. John thought the port (soup) was delicious.

11. Last week the cabinet (tourist) was visiting Boston.

12. Yesterday the cabinet (tourist) was busy all day.

13. He knew the yarn (tale) had been told well.

14. We hoped the yarn (tale) would not be told often.

15. Obviously the letter (square) was drawn by a child.

16. I saw the letter (square) was made from matchsticks.

17. I know the pen (zoo) is too tiny for an elephant.

18. I knew the pen (zoo) was too dirty for animals.

(Manuscript received September 4, 1985 revision accepted for publication January 13,1986 .) 